\title{
PhERF2, an ethylene-responsive element binding factor, plays an essential role in waterlogging tolerance of petunia
}

\author{
Dongmei Yin ${ }^{1}$, Daoyang Sun², Zhuqing Han', Dian Ni ${ }^{1}$, Ayla Norris ${ }^{3}$ and Cai-Zhong Jiang $\mathbb{C}^{3,4}$
}

\begin{abstract}
Ethylene-responsive element binding factors (ERFs) are involved in regulation of various stress responses in plants, but their biological functions in waterlogging stress are largely unclear. In this study, we identified a petunia (Petunia $x$ hybrida) ERF gene, PhERF2, that was significantly induced by waterlogging in wild-type (WT). To study the regulatory role of PhERF2 in waterlogging responses, transgenic petunia plants with RNAi silencing and overexpression of PhERF2 were generated. Compared with WT plants, PhERF2 silencing compromised the tolerance of petunia seedlings to waterlogging, shown as $96 \%$ mortality after 4 days waterlogging and 14 days recovery, while overexpression of PhERF2 improved the survival of seedlings subjected to waterlogging. PhERF2-RNAi lines exhibited earlier and more severe leaf chlorosis and necrosis than WT, whereas plants overexpressing PhERF2 showed promoted growth vigor under waterlogging. Chlorophyll content was dramatically lower in PhERF2-silenced plants than WT or overexpression plants. Typical characteristics of programmed cell death (PCD), DNA condensation, and moon-shaped nuclei were only observed in PhERF2-overexpressing lines but not in PhERF2-RNAi or control lines. Furthermore, transcript abundances of the alcoholic fermentation-related genes ADH1-1, ADH1-2, ADH1-3, PDC1, and PDC2 were reduced in PhERF2silenced plants, but increased in PhERF2-overexpressing plants following exposure to 12-h waterlogging. In contrast, expression of the lactate fermentation-related gene LDH was up-regulated in PhERF2-silenced plants, but downregulated in its overexpressing plants. Moreover, PhERF2 was observed to directly bind to the ADH1-2 promoter bearing ATCTA motifs. Our results demonstrate that PhERF2 contributes to petunia waterlogging tolerance through modulation of PCD and alcoholic fermentation system.
\end{abstract}

\section{Introduction}

Global climate change brings about a frequent occurrence of extreme rainfall events, and it increases the demand for improvement of plant tolerance to waterlogging ${ }^{1}$, which is defined as the state in which soil is saturated with water most of the time, restricting exposure to air and causing anaerobic conditions. Plants under waterlogging conditions undergo hypoxic stress with

Correspondence: Cai-Zhong Jiang (cjiang@ucdavis.edu)

${ }^{1}$ College of Ecology, Shanghai Institute of Technology, Shanghai 201418, China ${ }^{2}$ College of Landscape Architecture and Arts, Northwest A\&F University,

Yangling, Shaanxi 712100, China

Full list of author information is available at the end of the article.

These authors contributed equally: Dongmei Yin, Daoyang Sun difficulty in oxygen diffusion, resulting in a drop in photosynthesis, respiration, and chlorophyll accumulation ${ }^{2}$. Adaptation of plants to low oxygen levels takes place at three stages ${ }^{3}$. At the beginning, several signal transduction components are rapidly induced in plants, and then metabolic adaptation is initiated through fermentation pathways. Finally, programmed cell death (PCD) and cell wall autolysis cause morphological changes such as aerenchyma formation in adventitious roots ${ }^{4}$. PCD is closely related with the cellular phenomenon of DNA condensation and moon-shaped nuclei ${ }^{5}$. These molecular and morphological adaptations serve to promote oxygen retention and capture efficiencies for alleviating waterlogging stress.

\section{(c) The Author(s) 2019}

(c) (i) Open Access This article is licensed under a Creative Commons Attribution 4.0 International License, which permits use, sharing, adaptation, distribution and reproduction cc) in any medium or format, as long as you give appropriate credit to the original author(s) and the source, provide a link to the Creative Commons license, and indicate if changes were made. The images or other third party material in this article are included in the article's Creative Commons license, unless indicated otherwise in a credit line to the material. If material is not included in the article's Creative Commons license and your intended use is not permitted by statutory regulation or exceeds the permitted use, you will need to obtain permission directly from the copyright holder. To view a copy of this license, visit http://creativecommons.org/licenses/by/4.0/. 
Plants produce metabolic energy through fermentative glycolysis and not oxidative respiration in response to waterlogging stress ${ }^{6-8}$. In the case of oxygen deficiency, respiration varies from the aerobic to the anaerobic mode, which is implicated in glycolysis and fermentation ${ }^{9}$. The first step of fermentation pathway reveals that pyruvate decarboxylase (PDC) is responsible for catalysis of the conversion of pyruvate to acetaldehyde. Then acetaldehyde is converted to ethanol via alcohol dehydrogenase $(\mathrm{ADH})$, leading to regeneration of $\mathrm{NAD}^{+}$in dehydrogenase systems. This process plays a major role in the alcoholic fermentation pathway, and is vital for sustainment of glycolysis under hypoxic conditions ${ }^{10}$. Besides, the conversion of pyruvate to lactate by lactate dehydrogenase (LDH) also contributes to the production of $\mathrm{NAD}^{+}$. The functional characterization of anaerobic proteins (ANPs), such as PDC, ADH, and $\mathrm{LDH}$, have been reported in some plant species, including Arabidopsis ${ }^{11}$, salt marsh grass ${ }^{12}$, rice $^{9}$, pigeon pea ${ }^{10}$, and maize ${ }^{13}$.

The ethylene-responsive element binding factor (ERF) proteins are crucial transcriptional regulators in response to diverse biotic and abiotic stresses in plants. Members of the ERF family regulate stress responses mostly through the direct binding to specific promoter sequences (cisacting GCC box) of defense-related genes ${ }^{14}$, but certain members have different binding sites. For instance, AtRAP2. $2^{15}$ and AtRAP2.12 ${ }^{16}$ belonging to ERF-VII subgroup in Arabidopsis, specifically recognize the motif ATCTA in the promoter of downstream genes. ERF genes have been identified in a number of plants, including Arabidopsis ${ }^{17}$, rice ${ }^{18,19}$, soybean ${ }^{20}$, and wheat (Triticum aestivum $)^{21}$. Constitutive expression of soybean GmERF3 in transgenic tobacco plants reduces susceptibility to high salinity, dehydration, fungal, and viral diseases ${ }^{22}$. Ectopic overexpression of JERF1 and JERF3 increases resistance to drought and osmotic stress in tobacco and rice ${ }^{23,24}$. Transgenic Arabidopsis plants with overexpressed AtERF98 exhibit enhanced tolerance to salt via regulation of ascorbic acid synthesis ${ }^{25}$. Moreover, the biological role of ERFs in waterlogging stress has been reported previously. Overexpression of an ERF gene Sub1A leads to an enhanced tolerance to water submergence in rice ${ }^{26-28}$. Licausi et al. ${ }^{29}$ found that double mutants of hre1 and $h r e 2$, two hypoxia-inducible ERFs in Arabidopsis, display increased sensitivity to anoxia. HRE1 overexpression improves anoxia tolerance of transgenic Arabidopsis plants, and increases the PDC and ADH activities. Transgenic Arabidopsis plants constitutively expressing BnERF2.4 from Brassica napus exhibit enhanced submergence tolerance and alleviated oxidative damage ${ }^{30}$. However, the molecular mechanism of how ERFs regulate waterlogging tolerance remains largely unknown.

Petunia, an important horticultural plant that is highly sensitive to submergence, is an excellent model system for studies of waterlogging responses. In previous work, we identified a cluster of transcription factors during petunia flower development via transcriptomic analysis, including some ERFs ${ }^{31}$. We have recently reported a critical role of $P h E R F 2$ in antiviral RNA silencing and also observed that expression levels of PhERF2 were significantly induced by stress-related hormones including ethylene, abscisic acid, salicylic acid, and methyl jasmonate as well as abiotic stress treatments such as cold, $\mathrm{NaCl}$, and water stress ${ }^{32}$. The fact that roles of PhERF2 homologs in tolerance to abiotic stresses, such as salt ${ }^{33}$ and cold ${ }^{34}$, are characterized in other species prompts us to hypothesize that PhERF2 is involved in the stress regulation. Here, we report an additional function of PhERF2 in petunia waterlogging tolerance. $P h E R F 2$ silencing reduced petunia tolerance to waterlogging, and its overexpression increased the tolerance. Our results support an important role of PhERF2 in the regulation of waterlogging resistance in petunia.

\section{Materials and methods \\ Plant materials and growth conditions}

Petunia (Petunia $\times$ hybrida) cultivar 'Mitchell Diploid' was used for generation of stable transformants. Seeds of wild-type (WT) and homozygous T2 generation transgenic petunia plants were surface-sterilized with $75 \%$ ethanol and $5 \% \mathrm{NaClO}$. After rinsing five times with sterilized water, WT and transgenic petunia seeds were placed on Murashige and Skoog (MS) medium without antibiotics or containing $50 \mathrm{mg} \mathrm{L}^{-1}$ kanamycin, respectively. Two weeks post germination, transgenic petunia seedlings were transferred to non-antibiotic MS medium to continue growth for 1 week. Both were then transplanted into the soil mixture and kept at $23 / 19^{\circ} \mathrm{C}$ day/ night under a photoperiod of $12 / 12 \mathrm{~h}$ light/dark. To determine transcript abundances of genes in petunia plants exposed to waterlogging stress, uppermost or lower leaves at different times after treatment were harvested for RNA extraction.

\section{Generation of transgenic petunia plants}

A 339-bp fragment and a full length 1143-bp fragment harboring the ORF region of PhERF2 were PCR-amplified and cloned into pGSA1285 and pGSA1403 vectors for generating the RNAi and overexpression constructs, respectively, as previously described ${ }^{32}$. The constructs were transformed into Agrobacterium tumefaciens strain LBA4404 (Takara, Otsu, Shiga, Japan) via electroporation. For the electroporation, $20 \mu \mathrm{l}$ of LBA4404 competent cells were mixed with $0.1-0.2 \mu \mathrm{g}$ of constructed plasmids and subjected to an electrical pulse at $2.5 \mathrm{kV}$ and $400 \Omega$ in a cold cuvette using a Gene Pulser (Bio-Rad, Richmond, CA, USA). The cells were suspended in $1 \mathrm{ml}$ of liquid LB medium for $2 \mathrm{~h}$ of incubation at $28^{\circ} \mathrm{C}$, and then spread on 
solid LB medium containing appropriate antibiotics for selection of positive colonies. Leaf discs of petunia 'Mitchell Diploid' were used for inoculation with Agrobacterium according to previous description ${ }^{35}$. The resulting transformants were selected on MS plates supplemented with $100 \mathrm{mg} \mathrm{L}^{-1}$ kanamycin $^{36}$. After a continuous cultivation, the PhERF2-RNAi (1A, 1B, and 4B) and PhERF2-overexpressing (C, D, and I) lines in the T2 generation exhibiting 100\% survival on MS selection medium were obtained and used for further waterlogging assay.

\section{Waterlogging treatments}

To examine the impact of waterlogging stress on WT, PhERF2-RNAi, and -overexpressing plants, the following treatments were applied to 5-week-old petunia plants before morphology was recorded: $0,24 \mathrm{~h}$ waterlogging, 4 days waterlogging +14 days recovery. All treatments were replicated 5 times and 16 plants were used for each replication. Plants were subjected to $24 \mathrm{~h}$ continuous flooding treatment by putting small pots with plants into larger ones, which were then excessively irrigated with tap water at room temperature. For flooding experiments, the water level was kept at $2-3 \mathrm{~cm}$ higher than soil surface during the flooding process. After the treatment, a complete drainage was ensured through a drilled hole located underneath the pot. The plants untreated with flooding were used as a control. We hypothesize that transcriptional responses to waterlogging occur much earlier than physiological and metabolic processes and morphological alteration. Therefore, for expression analysis of $A D H \mathrm{~s}$, $P D C$ s, and $L D H$, leaf samples with three biological replicates from 6-week-old WT and transgenic plants were collected at $12 \mathrm{~h}$ after waterlogging treatments.

\section{Measurement of chlorophyll content}

Total chlorophyll $(\mathrm{a}+\mathrm{b})$ content was measured as described previously ${ }^{37}$. Briefly, fresh leaf samples $(0.1 \mathrm{~g})$ were extracted for $24 \mathrm{~h}$ with $10 \mathrm{ml}$ of acetone:anhydrous ethanol $(1: 1, \mathrm{v} / \mathrm{v})$ mixture solution in the dark at room temperature. The absorbance of resulting solvent was measured at both 663 and $645 \mathrm{~nm}$ using a Beckman Coulter DU 800 spectrophotometer (Beckman Coulter Inc., Fullerton, CA, USA). Chlorophyll contents were calculated based on the fresh weight.

\section{Cell death assay}

The $20-30 \mathrm{~mm}$ of distal roots from WT and transgenic lines at various times after treatment with waterlogging were fixed by immersion in a mixture solution of formalin:ethanol:glacial acetic acid (18:1:1, v/v) at room temperature for at least $24 \mathrm{~h}$ under vacuum. After that, the samples were washed three times in $0.1 \mathrm{M}$ phosphate buffer ( $\mathrm{pH}$ 7.4) and dehydrated in a graded series of ethanol (70-100\%), followed by subsequent air drying. A confocal laser-scanning microscope (LSM 700, Carl Zeiss, Germany) was used for examination of the cells. The histological detection of root nuclei was performed through staining with $1 \mathrm{mg} \mathrm{L}^{-1}$ DAPI (4', 6-diamidino-2phenylindol dihydrochloride) in $10 \mathrm{mM}$ Tris $/ \mathrm{HCl}(\mathrm{pH}$ 7.4), and then examining under a confocal laser-scanning microscope. Over 100 cells for each sample were observed for any DNA condensation and moon-shaped nuclei, an indication of PCD.

\section{Quantitative real-time PCR}

Total RNA extraction was performed on petunia leaves using TRIzol reagent (Invitrogen, Carlsbad, CA, USA). The isolated RNA samples were purified with RNase-free DNase I (Promega, Madison, WI, USA), and subsequently transcribed to first-strand cDNA using oligo $(\mathrm{dT})_{20}$ primer with SuperScript III reverse transcriptase (Invitrogen, Carlsbad, CA, USA), according to manufacturer's instructions. Quantitative real-time PCR analysis was conducted using the SYBR Green PCR Master Mix $(2 \times)$ (ABI7300; Applied Biosystems, Foster City, CA, USA) with cDNA being templates. Constitutively expressed $26 S$ ribosomal RNA was used as a reference gene to standardize $\mathrm{CDNA}^{38,39}$. Oligonucleotide primers used for detection of gene transcripts are shown in Supplementary Table S1.

\section{Electrophoretic mobility shift assay}

Electrophoretic mobility shift assay (EMSA) was performed as previously described ${ }^{40}$ with minor changes. The complete coding region of PhERF2 was amplified and cloned into the pET28a vector. The overexpression of the corresponding PhERF2 protein was achieved through the culturing of transformed E. coli Rosetta (DE3) cells by addition of the inducer isopropylthio- $\beta$-galactoside at $16^{\circ} \mathrm{C}$ for $24 \mathrm{~h}$. The recombinant proteins were extracted and applied to the column (HisTrap HP, GE) for purification according to the manufacturer's instructions. The biotin-labeled WT or site-directed mutant probe containing a 35-bp oligonucleotide in the ADH1-2 promoter was amplified using the primers Bio-pADH1-2-F/ pADH1-2-R or Bio-mpADH1-2-F/mpADH1-2-R, respectively (Supplementary Table S1). The non-labeled probe served as the competitor. Subsequently, the interaction of PhERF2 with ADH1-2 promoter was carried out using the LightShift EMSA Optimization and Control Kit (Pierce, Thermo Fisher Scientific, MA, USA). The protein-DNA complexes were separated by electrophoresis on a Tris-glycine-buffered $6 \%$ non-denaturing polyacrylamide gel. The binding signals of PhERF2 with biotin-labeled probe were detected using the Chemiluminescent Nucleic Acid Detection Module Kit (Pierce, Thermo Fisher Scientific, MA, USA). 


\section{Dual luciferase assay}

Dual luciferase assay was performed using a method previously described ${ }^{41}$. The full-length coding sequence of PhERF2 was amplified and inserted into pGreenII62-SK vector as the effector, driven by CaMV $35 \mathrm{~S}$ promoter, and the empty vector was used as a control. To generate the reporter construct, a 1256-bp ADH1-2 promoter sequence bearing four putative binding sites of PhERF2 (Supplementary Fig. S1) was ligated into transient expression pGreenII0800-LUC vector, with the PhERF2 targeted candidate $A D H 1-2$ promoter driving a firefly luciferase (LUC) gene and a CaMV 35 promoter driving a Renilla luciferase (REN) gene. The primers used for these two constructs are listed in Supplementary Table S1. To examine the transactivation of PhERF2 to ADH1-2 promoter, the $A$. tumefaciens GV3101 cells transformed with constructed effector and reporter plasmids were used to co-infiltrate 6-leaf-stage petunia seedlings. The enzyme activities of LUC and REN were detected using dualluciferase assay kit (Promega, Madison, WI, USA) on a luminometer Tecan Infinite M200 (Männedorf, Switzerland). The promoter activities were indicated by the LUC/ REN ratio.

\section{Statistical analysis}

All experiments were carried out with a minimum of three biological replicates for different individual plants. The significance of difference was determined through Student's $t$ test at $P$ value $<0.05$, using JMP (Version 11.0) software (SAS Institute Inc., Cary, NC, USA).

\section{Results}

\section{PhERF2 affects tolerance of petunia to waterlogging}

To investigate the role of PhERF2 in waterlogging responses, transgenic petunia plants with RNAi silencing (lines $1 \mathrm{~A}, 1 \mathrm{~B}$, and $4 \mathrm{~B}$ ) and overexpression (lines $\mathrm{C}$, D, and I) of PhERF2 were generated, respectively. Waterlogging treatment triggered wilting and leaf chlorosis in all tested plants of transgenic lines, but the symptoms occurred earlier and more seriously in PhERF2-RNAi lines than PhERF2-overexpressing and WT plants (Fig. 1). After waterlogging for 4 days and recovery for 14 days, the PhERF2-silenced plants were severely damaged and suffered 96\% mortality, whereas nearly all PhERF2-overexpressing plants survived and displayed a quicker and stronger recovery than WT plants (Fig. 1). At $24 \mathrm{~h}$ post waterlogging, particularly, older leaves at the bottom of the plant became chlorotic and rotten in PhERF2-RNAi lines, while the leaves of WT and transgenic lines overexpressing PhERF2 exhibited much milder symptoms with relatively healthy leaves, compared with the nonwaterlogged controls (Fig. 2).

\section{Chlorophyll accumulates differently in WT and PhERF2 transgenic plants under waterlogging}

After $24 \mathrm{~h}$ of exposure to waterlogging stress, the petunia WT, PhERF2-RNAi, and -overexpressing lines showed variable leaf chlorosis and yellowing symptoms (Figs. 2, 3a). To further determine the leaf symptoms change, we measured chlorophyll contents of older leaves at the bottom of the WT and transgenic plants. By comparison with control lines without waterlogging stress, the leaf chlorophyll levels of WT and PhERF2 transgenic lines were decreased rapidly and significantly in response to waterlogging (Fig. $3 \mathrm{~b}$ ). The ratio of chlorophyll content at $24 \mathrm{~h}$ post treatment (hpt) to that at $0 \mathrm{hpt}$ in WT plants was substantially higher than in PhERF2silenced lines but lower than in PhERF2-overexpressing lines (Fig. 3b). Specifically, the chlorophyll content was decreased by $78.3 \%$ in WT plants, by $74.9 \%, 79.9 \%$, and $59.6 \%$ in three overexpression lines $(\mathrm{C}, \mathrm{D}$, and $\mathrm{I})$, and by $98.8 \%, 93.8 \%$, and $95.9 \%$ in three silencing lines $(1 \mathrm{~A}, 1 \mathrm{~B}$, and $4 \mathrm{~B})$ at $24 \mathrm{~h}$ of waterlogging stress, respectively, compared to corresponding unstressed control.

\section{Waterlogging treatment induces PhERF2 expression}

To study the expression of PhERF2 in response to waterlogging stress, 5-week-old plants of WT, PhERF2-

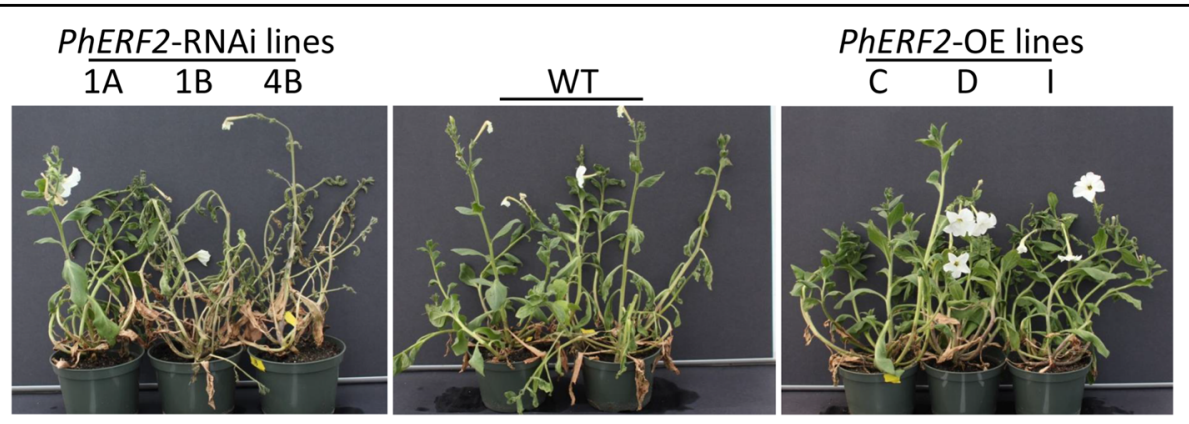

Fig. 1 Representative phenotypes of PhERF2-silenced and -overexpressing seedlings exposed to waterlogging and recovery. Five-week-old seedlings of wild type (WT), PhERF2-RNAi (1A, 1B, and 4B), and PhERF2-overexpressing (OE) lines (C, D, and I) were subjected to flooding treatment for 4 days, and then recovery for 14 days. Photographs were taken at 14 days post recovery 


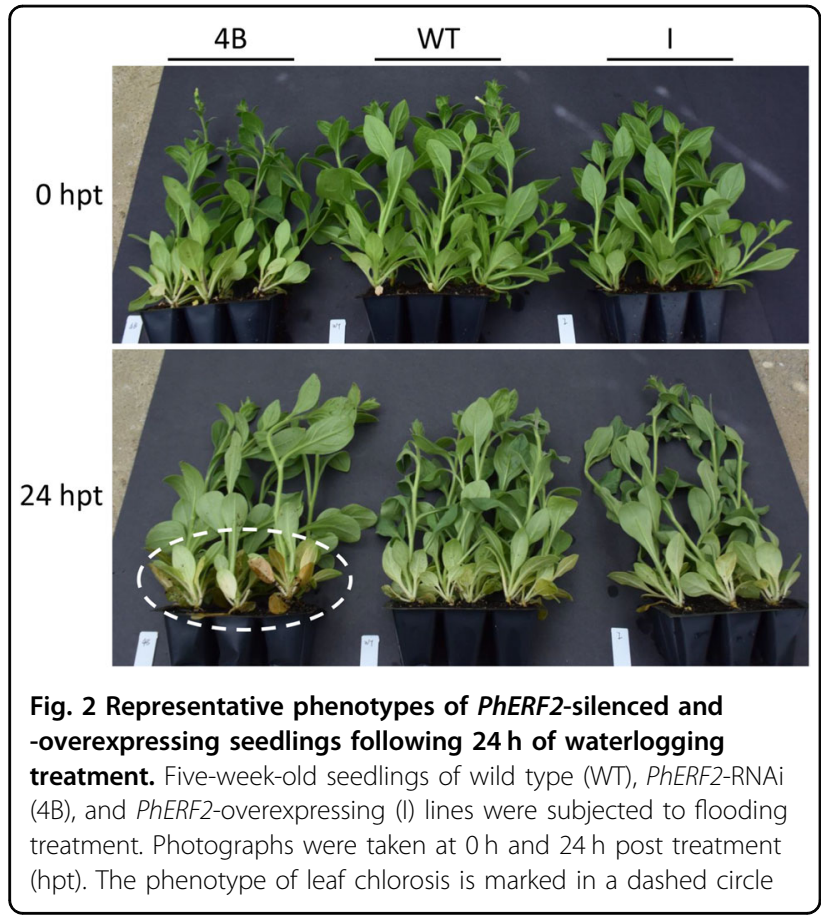

overexpressing (D and I) and PhERF2-RNAi (1A and 4B) were waterlogged, and transcript levels of PhERF2 in uppermost leaves were determined by quantitative realtime PCR. PhERF2 expression levels were significantly higher in the overexpression lines and dramatically lower in the silenced lines than in the WT plants (Fig. 4). Transcripts of PhERF2 were markedly up-regulated by waterlogging in the WT and overexpression lines, especially line D and I. A 2.1-fold and 3.7-fold increase of PhERF2 expression in response to $24 \mathrm{~h}$ of waterlogging was observed for the overexpression lines, respectively. Two PhERF2-RNAi lines showed remarkable reduction in transcript abundance of PhERF2 under waterlogging stress (Fig. 4).

\section{Overexpression of PhERF2 induced PCD in response to waterlogging}

To better understand the impact of PhERF2 on waterlogging tolerance at the cellular level, we assessed the cell microstructures of roots from WT and transgenic plants untreated and treated with waterlogging. In the nonwaterlogged roots, no cell death was observed, and all the cells and inner nuclei remained intact (Fig. 5). DAPI staining detected cell death in the roots of WT and PhERF2-RNAi (4B) plants after $24 \mathrm{~h}$ of waterlogging. Waterlogging caused a loss of cell integrity via lysis and extensive collapse of cell internal structures, with many cells losing protoplasms and generating distorted organelles (Fig. 5). In contrast, waterlogging stress resulted in DNA condensation and the formation of moon-shaped
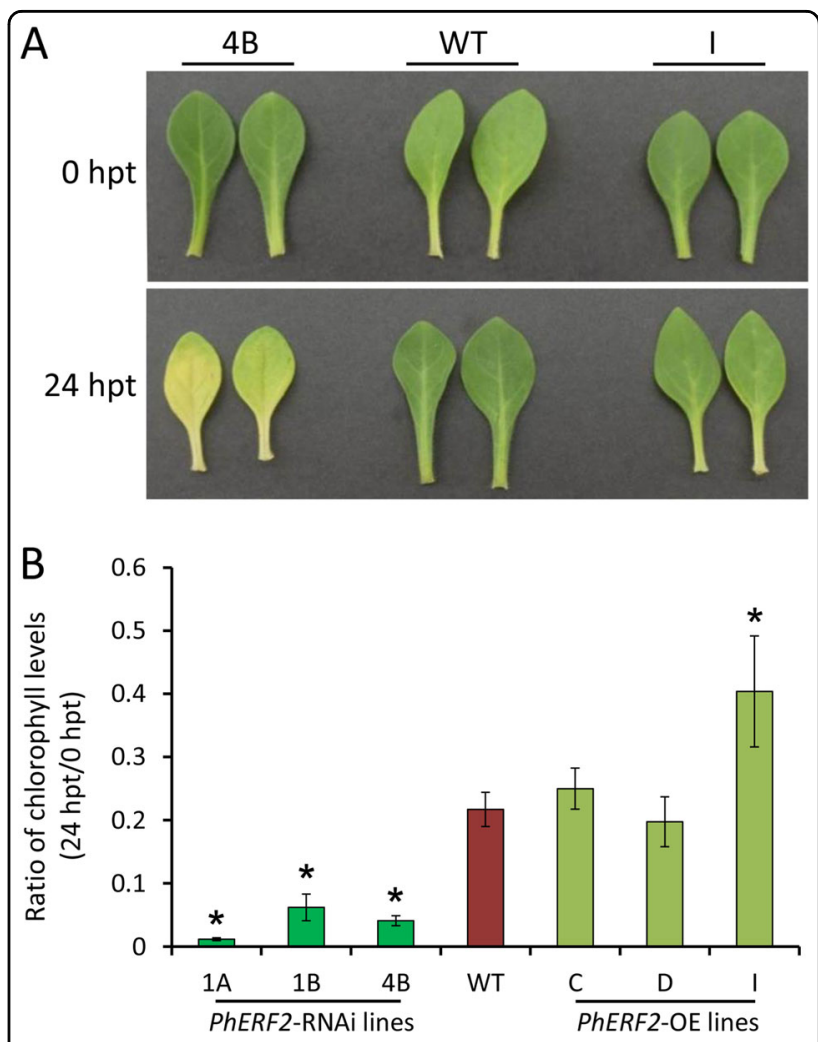

Fig. 3 Chlorophyll levels of leaves from PhERF2-silenced and -overexpressing seedlings under waterlogging conditions. Representative phenotypes of leaves (a) and ratio of chlorophyll levels (b) of 5-week-old WT, PhERF2-RNAi, and PhERF2-overexpressing (OE) lines subjected to flooding treatment. The basal leaves photographed were harvested at the bottom of plants $0 \mathrm{~h}$ and $24 \mathrm{~h}$ post treatment (hpt), and the percentage of chlorophyll content was calculated at 24/ 0 hpt. Data represent the means $( \pm S D)$ of three biological replicates. Asterisks denote statistical significance using Student's $t$ test at $P<$ 0.05

nuclei in waterlogging-tolerant PhERF2-overexpressing lines (I) (Fig. 5).

\section{PhERF2 mediates alcoholic and lactate fermentations}

Hypoxia resulting from waterlogging initiates a switch from aerobic respiration to anaerobic fermentation via activation of the glycolytic and fermentation pathways. To study the correlation of PhERF2 with fermentation pathways, transcript levels of a number of relevant genes, including three homologous genes to $A D H 1$, two PDC genes, and one LDH gene, were examined. Compared to control plants without waterlogging, transcript abundances of the alcoholic fermentation-related genes $A D H 1$ 1, ADH1-2, ADH1-3, PDC1, and PDC2 were decreased in PhERF2-silenced plants but increased in PhERF2-overexpressing plants under waterlogging treatment (Fig. 6). However, PhERF2-silenced plants showed increased transcript abundances of the lactate fermentation-related gene $L D H$, while PhERF2-overexpressing plants showed 

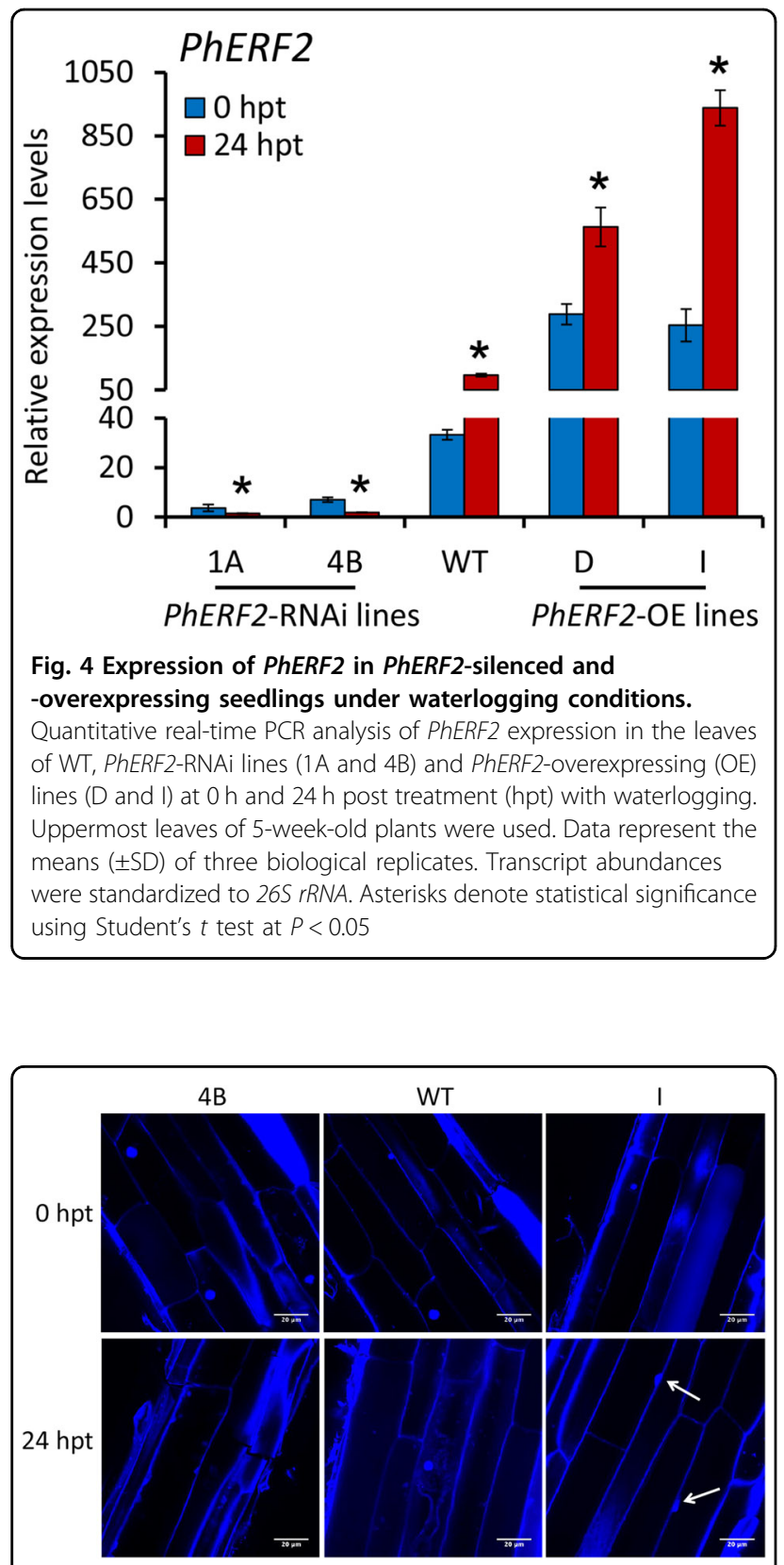

Fig. 5 The programmed cell death in the roots of PhERF2overexpressing lines subjected to waterlogging. DAPI staining was used to identify cell death at $\mathrm{O} h$ and $24 \mathrm{~h}$ post treatment (hpt) with waterlogging. Arrows denote the moon-shaped nuclei

reduced $L D H$ expression levels under waterlogging conditions. Thus, overexpression of PhERF2 may activate the expression of alcoholic fermentation enzyme genes and alleviate the hypoxic conditions in the overexpression lines, protecting plants from waterlogging damage. The results suggest that a main pathway of $\mathrm{NAD}^{+}$regeneration in waterlogged PhERF2-overexpressing plants is possibly not lactate fermentation but alcoholic fermentation. On the contrary, PhERF2-silenced plants are probably dependent on lactate fermentation against waterlogging stress.

\section{PhERF2 binds to the ADH1-2 promoter}

To further investigate the regulatory mechanism of PhERF2, we searched the promoter regions of those genes with significantly changed expression in transgenic lines. Based on the previously reported binding sites of AtRAP2.12 16 , an ortholog of PhERF2, we found four motifs with the core ATCTA (or TAGAT in the opposite strand) element in the $1.5 \mathrm{~kb}$ promoter region upstream of the ADH1-2 coding sequence (Supplementary Fig. S1). A 35 -bp fragment spanning positions -786 to -820 of the ADH1-2 promoter was used as a probe for EMSA experiments (Fig. 7a). A clear binding of PhERF2 protein to the biotin-labeled target probe was visualized as slowed bands in the polyacrylamide gel, whereas no signals were detected from the protein-mutant probe (m-probe) complex (Fig. 7b). Additionally, a dual luciferase transient expression assay based on the effector and reporter constructs (Supplementary Fig. S2) was conducted to test whether the transactivation of $A D H 1-2$ promoter by PhERF2 occurred in petunia plants. Compared with empty vector control, the co-expression of $35 S:: P h E R F 2$ and pADH1-2::LUC resulted in a 32-fold increase in LUC activity (Fig. 7c). The results revealed the direct interaction between PhERF2 and ADH1-2 promoter.

\section{Discussion}

In this study, we analyzed the morphological and physiological variations between WT and transgenic petunia plants, PhERF2-overexpressing and PhERF2-RNAi lines, under waterlogging conditions. There were no significant differences in morphology of plants without waterlogging treatment (Figs. 2, 3). After $24 \mathrm{~h}$ of waterlogging treatment, the leaves of the PhERF2-RNAi lines became yellow and withered. The results were in accordance with those reported previously about waterlogging effects on chrysanthemum $^{42}$.

The waterlogging treatment resulted in reduced respiration and photosynthesis of plants due to lack of oxygen $^{43}$. The plants recovered once the waterlogging ceased. After a successive waterlogging and recovery treatment, the PhERF2-RNAi plants were almost dead with all the leaves being severely wilted (Fig. 1), whereas the PhERF2-overexpressing plants were still alive with normal growth, suggesting that they probably used the PhERF2-regulated pathways to recover from the damage. Our data demonstrated that PhERF2 functions as a positive regulator in plant defense against waterlogging stress. Despite the recovery time of up to 14 days, in contrast to overexpression lines, the WT plants failed to completely recover and showed leaf chlorosis and wilting 

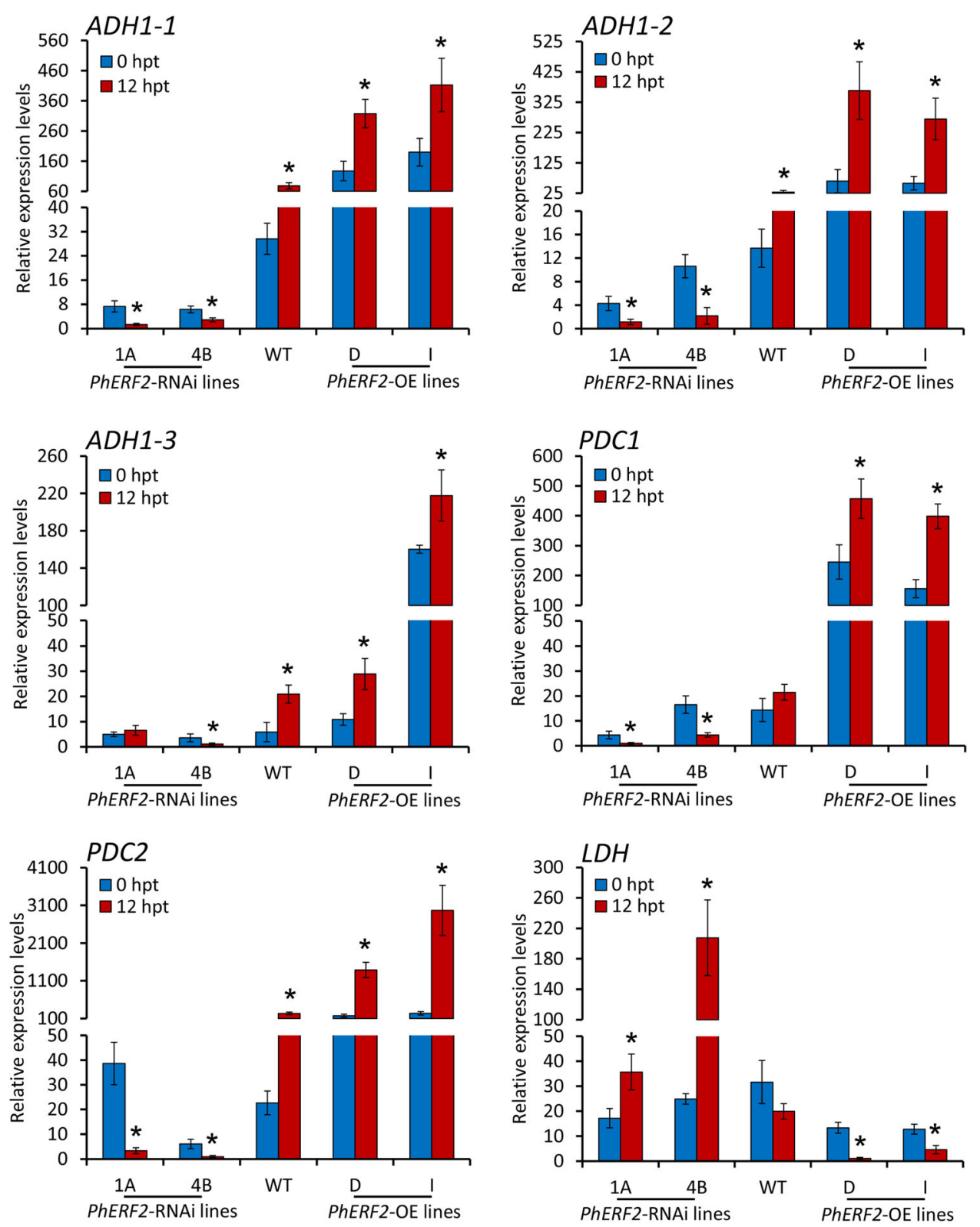

Fig. 6 Expression of lactate and alcoholic fermentation-related genes in PhERF2-silenced and -overexpressing seedlings under waterlogging conditions. Quantitative real-time PCR analysis of transcript abundances for ADH1-1, ADH1-2, ADH1-3, PDC1, PDC2, and LDH in the leaves of WT, PhERF2-RNAi lines (1A and 4B) and PhERF2-overexpressing (OE) lines ( $\mathrm{D}$ and $\mathrm{I}$ ) at $0 \mathrm{~h}$ and $12 \mathrm{~h}$ post treatment (hpt) with waterlogging. The leaves at the bottom of 6-week-old plants were used for expression analysis. Data represent the means $( \pm S D)$ of three biological replicates. 265 rRNA was used as an internal control. Asterisks denote statistical significance using Student's $t$ test at $P<0.05$

symptoms. It is quite likely that the plants may suffer some damage during the recovery period after waterlogging stress in this experiment. The physiological changes of WT and PhERF2 transgenic plants during the transition phase from waterlogging to recovery require further examination.

Under waterlogging conditions, the levels of leaf chlorophyll decline significantly in plants ${ }^{10,44}$. For example, waterlogging results in reduced leaf chlorophyll content in both waterlogging-tolerant and -susceptible plants of pigeon pea (Cajanus cajan) ${ }^{45}$. In our study, the chlorophyll content also declined in both WT and transgenic lines under waterlogging conditions, but the chlorophyll levels were higher in PhERF2-overexpressing lines than in PhERF2-RNAi lines (Fig. 3). Plants treated with flooding suffer from hypoxia and chlorophyll degradation $^{2}$. It appears that The PhERF2-RNAi lines suffered more from waterlogging stress than WT or 


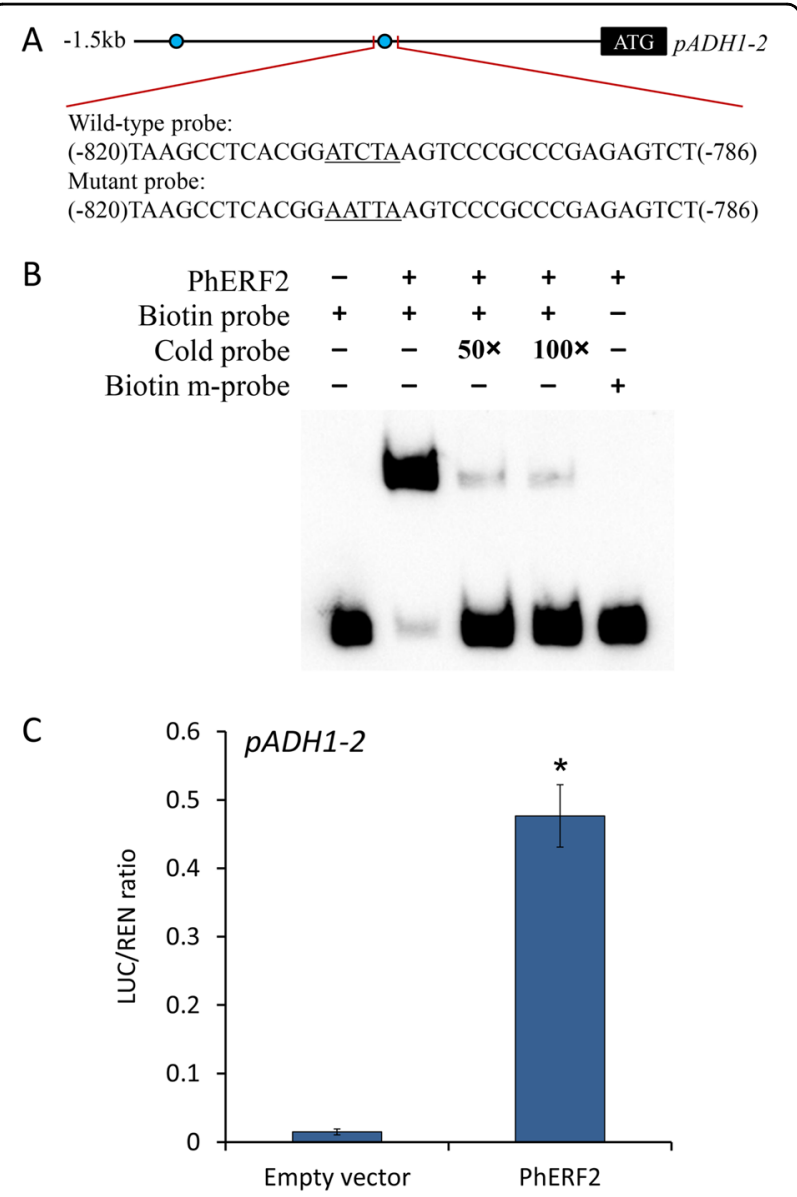

Fig. 7 Transactivation of the ADH1-2 promoter by PhERF2. a Graphic representation of petunia $A D H 1-2$ promoter ( $P A D H 1-2)$ with a $1.5 \mathrm{~kb}$ region upstream of the coding sequence. Two putative PhERF2 binding sites (ATCTA) are marked by blue circles. The probe sequences used for electrophoretic mobility shift assay (EMSA) are indicated, with the wild-type cis-element and its nucleotide substitutions being underlined, respectively. $\mathbf{b}$ EMSA of PhERF2 binding to the biotinlabeled probe. Non-labeled probes (cold) at 50- and 100-fold concentrations were added for competition, and mutant probe ( $\mathrm{m}$ probe) for binding specificity test. c Dual luciferase transient expression assay of the ADH1-2 promoter (pADH1-2). The binding activity was expressed as a ratio of LUC to REN. LUC, firefly luciferase; REN, Renilla luciferase. Error bars represent the standard error of the means from three biological replicates. Statistical significance was determined using Student's $t$ test $(P<0.05)$ and denoted by asterisks

overexpression lines. It seems likely that the chlorosis in the older leaves at the bottom of the plant is attributed to the translocation of nitrogen from lower, older to upper younger leaves under threat from waterlogging ${ }^{46}$.

Expression analysis indicated that PhERF2 was significantly up-regulated in WT and overexpression plants under flooding conditions (Fig. 4). The PhERF2 homologs in other species have similar expression profiles after treatments with abiotic stresses. Expression levels of $N t C E F 1$ from tobacco are elevated under cold and salt conditions $^{47}$. Salt treatment increases transcript abundances of $J E R F 1^{33}$ and $J E R F 3^{48}$ in tobacco, and transgenic plants overexpressing these two genes showed decreased susceptibility to salt stress. Pepper CaPF1 expression is markedly induced by low temperature and salt treatments, and ectopic expression of this gene confers tolerance to freezing in Arabidopsis ${ }^{34}$. Besides waterlogging tolerance, thus, a possible role of PhERF2 in plant tolerance to various abiotic stresses should be further examined in the future. Furthermore, up-regulation of PhERF2 under waterlogging suggested a critical involvement of PhERF2 in plant against hypoxic stress and further recovery from waterlogging damage.

Aerenchyma formation occurs following programmed cell death (PCD), which facilitates oxygen capture of waterlogged tissues ${ }^{49}$, eases the hypoxic stresses, and improves the recovery and maintenance of aerobic respiration in plants under waterlogging ${ }^{50,51}$. The occurrence of $\mathrm{PCD}$ under waterlogging raises the survival chances of many plant species ${ }^{52-54}$. At the morphoanatomical level, the responses of PhERF2-overexpressing plants to hypoxia were observed with induced PCD, probably leading to aerenchyma development in the roots (Fig. 5). It represents a positive adaptation to waterlogging ${ }^{55}$, since aerenchyma is beneficial to capture oxygen and to store and exchange gases within the waterlogged parts of plants ${ }^{50}$. However, PhERF2-RNAi plants may not be able to respond in any of these ways due to cell damage, thereby failing to survive under waterlogging stress. It seems likely that PhERF2 is involved in the transcriptional regulation of PCD, generally acting as a precursor for aerenchyma formation in plants exposed to waterlogging.

The waterlogging stress affects diverse physiological and metabolic processes in plants ${ }^{56,57}$. One major pathway to be affected is glycolytic fermentation, particularly manifesting as an increase in alcohol fermentation with involvement of two key enzymes, $\mathrm{PDC}$ and $\mathrm{ADH}^{9}$. Induction of LDH-catalyzed lactate fermentation has also been demonstrated in some plant species at the initial stage of hypoxia ${ }^{58}$. Although PhERF2-overexpressing plants responded during waterlogging with an elevation in transcript abundances of $P D C$ and $A D H, L D H$ was not up-regulated but down-regulated (Fig. 6). This indicates that lactate fermentation rather than alcohol fermentation predominantly contributes to $\mathrm{NAD}^{+}$regeneration in waterlogged PhERF2-overexpressing plants, while waterlogged PhERF2-silenced plants rely on lactate fermentation, which is a typical feature of plants sensitive to hypoxia $^{59}$. This is consistent with our previous results in the waterlogging-susceptible chrysanthemum cultivar '13$13^{, 60}$ and Dendranthema nankingense (Nakai) Tzvel ${ }^{37}$. Therefore, activation of alcoholic fermentation was considered as one effective strategy for plants to survive 


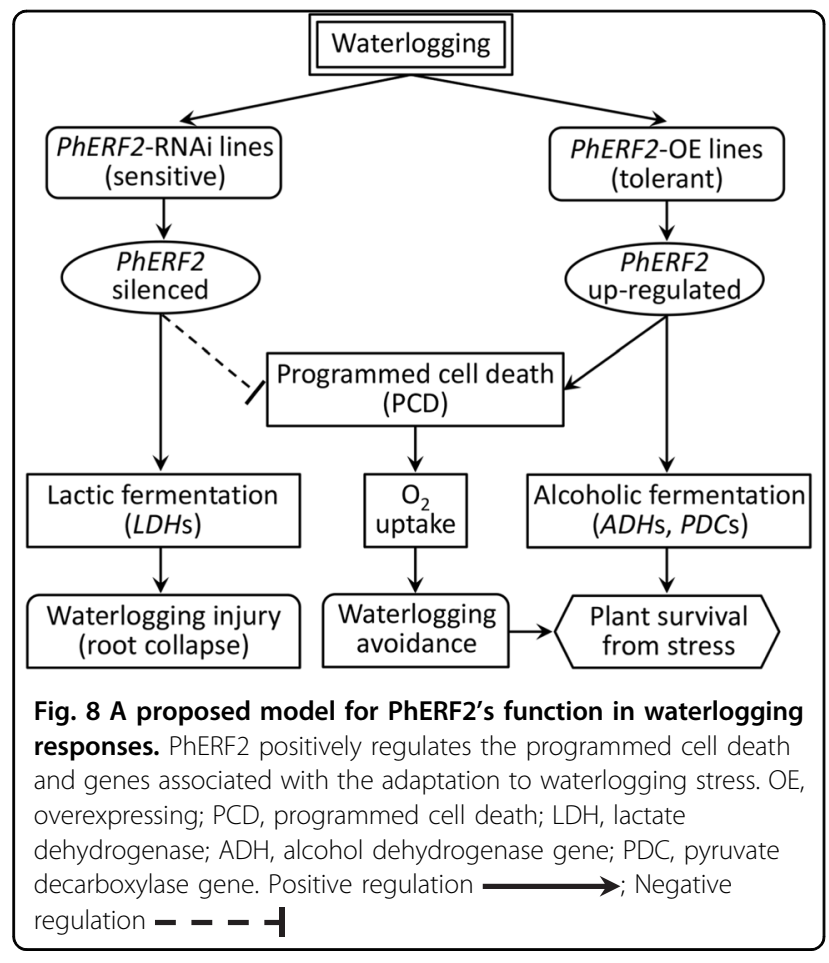

under strict anaerobiosis, as demonstrated in the seedlings of cucumber ${ }^{61}$ and chrysanthemum ${ }^{62}$ upon exposure to waterlogging stress.

ERFs represent a large family of transcription factors implicated in diverse biological processes, such as plant growth, development, and stress responses ${ }^{63}$. In Arabidopsis, approximately 122 putative ERF genes with conserved AP2/ERF domains are found in its genomic $\mathrm{DNA}^{64}$. Although many stress-related members are known to bind GCC box elements sharing a core AGCCGCC motif ${ }^{65}$, the binding specificity for various ERFs transcription factors appears to be very complicated. Here, our data revealed the specific activation of ADH1-2 promoter containing ATCTA motif by PhERF2 (Fig. 7), which is consistent with previous reports on the binding activity of AtRAP2.12 ${ }^{16}$, a homolog of PhERF2.

Survival of plants under waterlogging stress is associated with avoidance/escape and endurance ${ }^{66}$. Petioles of submerged Rumex palustris plants elongate to allow the leaf lamina to protrude from the water thus restoring normal respiration ${ }^{67}$. Similarly, internode elongation occurs to avoid waterlogging stress in submerged rice ${ }^{68}$. This escape response is modulated by the endogenous hormone ethylene, an important signal in response to submergence $^{62}$. For lowland rice, the waterlogging response involves endurance rather than escape ${ }^{66}$. In this work, we proposed a model of $P h E R F 2$ 's role in tolerance of petunia to waterlogging (Fig. 8). PhERF2 expression was increased in WT and PhERF2-overexpressing lines after waterlogging. Modulation of PhERF2 expression affected the expression of alcoholic or lactate fermentation-related genes. As a less efficient energy supplier than aerobic respiration, anaerobic fermentation produces the toxic byproducts ethanol and acetaldehyde, leading to cellular metabolism disturbance and root collapse. Thus the timing of the shift from alcoholic to lactic fermentation could be an essential indicator of plant survivability under hypoxia and reduce damage ${ }^{69}$.

It is worth mentioning that PhERF2 may participate in the formation of lysigenous aerenchyma through $\mathrm{PCD}$ in the roots of overexpression lines. This tissue is responsible for oxygen supplies to submerged roots and therefore alleviates hypoxia. This kind of avoidance strategy is widely employed in plants ${ }^{49,52,66,70,71}$. By comparison, the silenced lines without PCD appear to activate the lactic fermentation but not alcoholic fermentation pathway. Although this brings about temporary alleviation of energy shortage, it is insufficient to satisfy the ATP demand and simultaneously produces byproducts lactic acid disturbing cellular metabolism ${ }^{13}$. Thus in the waterlogging-susceptible PhERF2-RNAi lines, excessive accumulation of these byproducts might cause root collapse ultimately.

Our results provide new evidence that PhERF2 transcriptionally regulates the PCD and genes of alcoholic fermentation system to protect plants from anaerobic respiration damage, and therefore plays an important role in defense responses against waterlogging stress. EMSA and dual luciferase assays confirmed the direct binding of PhERF2 to ADH1-2 promoter in petunia. However, the mechanism on how PhERF2 and its target gene synergistically modulate plant defense against waterlogging is still unclear. To further dissect the biological function of $P h E R F 2$ in response to waterlogging, future studies should include comprehensive transcriptomic or metabolomic analyses in PhERF2 transgenic plants.

\section{Acknowledgements}

We are very grateful to Lee Ann Richmond and Pilong Liu for their technical assistance. This work was partially supported by the National Science Foundation of China (grant numbers 31701963 and 31801895) and United States Department of Agriculture (USDA) CRIS project 5306-21000-019-00D.

\section{Author details}

${ }^{1}$ College of Ecology, Shanghai Institute of Technology, Shanghai 201418, China. ${ }^{2}$ College of Landscape Architecture and Arts, Northwest A\&F University, Yangling, Shaanxi 712100, China. ${ }^{3}$ Crops Pathology \& Genetic Research Unit, United States Department of Agriculture, Agricultural Research Service, Davis, CA 95616, USA. ${ }^{4}$ Department of Plant Sciences, University of California Davis, Davis, CA 95616, USA

\section{Author contributions}

C.J. and D.Y. designed the research. D.Y., D.S., Z.H., A.N., and D.N. conducted the experiments. C.J., D.Y., and D.S. analyzed the data. D.Y. and D.S. wrote the manuscript. D.S., A.N., and C.J. revised the manuscript and improved the English.

Conflict of interest

The authors declare that they have no conflict of interest. 
Supplementary Information accompanies this paper at (https://doi.org/ 10.1038/s41438-019-0165-z).

Received: 25 December 2018 Revised: 1 May 2019 Accepted: 9 May 2019 Published online: 01 July 2019

\section{References}

1. IPCC. Climate Change 2007: Contribution of working group I to the fourth assessment report of the intergovernmental panel on climate change. (Cambridge University Press, Cambridge, 2007).

2. Jackson, M. \& Colmer, T. Response and adaptation by plants to flooding stress. Ann. Bot. 96, 501-505 (2005)

3. Dennis, E. S. et al. Molecular strategies for improving waterlogging tolerance in plants. J. Exp. Bot. 51, 89-97 (2000)

4. Purnobasuki, H. \& Suzuki, M. Aerenchyma formation and porosity in root of a mangrove plant, Sonneratia alba (Lythraceae). J. Plant Res. 117, 465-472 (2004).

5. Pennell, R. I. \& Lamb, C. Programmed cell death in plants. Plant Cell 9, 1157-1168 (1997)

6. Ismail, A. M., Ella, E. S., Vergara, G. V. \& Mackill, D. J. Mechanisms associated with tolerance to flooding during germination and early seedling growth in rice (Oryza sativa). Ann. Bot. 103, 197-209 (2009).

7. James, C. S. et al. Does stream flow structure woody riparian vegetation in subtropical catchments? Ecol. Evol 6, 5950-5963 (2016).

8. Capon, S. J., James, C. S., Williams, L. \& Quinn, G. P. Responses to flooding and drying in seedlings of a common Australian desert floodplain shrub: Muehlenbeckia florulenta Meisn. (tangled lignum). Environ. Exp. Bot. 66, 178-185 (2009).

9. Kato-Noguchi, H. \& Morokuma, M. Ethanolic fermentation and anoxia tolerance in four rice cultivars. J. Plant Physiol. 164, 168-173 (2007).

10. Kumutha, D., Sairam, R. K., Ezhilmathi, K., Chinnusamy, V. \& Meena, R. C. Effect of waterlogging on carbohydrate metabolism in pigeon pea (Cajanus cajan L.): Upregulation of sucrose synthase and alcohol dehydrogenase. Plant Sci. 175, 706-716 (2008).

11. Ismond, K. P., Dolferus, R., de Pauw, M., Dennis, E. S. \& Good, A. G. Enhanced low oxygen survival in Arabidopsis through increased metabolic flux in the fermentative pathway. Plant Physiol. 132, 1292-1302 (2003).

12. Maricle, B. R., Crosier, J. J., Bussiere, B. C. \& Lee, R. W. Respiratory enzyme activities correlate with anoxia tolerance in salt marsh grasses. J. Exp. Mar. Biol. Ecol. 337, 30-37 (2006).

13. Vodnik, D., Strajnar, P., Jemc, S. \& Mačeka, I. Respiratory potential of maize (Zea mays L.) roots exposed to hypoxia. Environ. Exp. Bot. 65, 107-110 (2009).

14. Ohmetakagi, M. \& Shinshi, H. Ethylene-inducible DNA binding proteins that interact with an ethylene-responsive element. Plant Cell 7, 173-182 (1995).

15. Welsch, R., Maass, D., Voegel, T., DellaPenna, D. \& Beyer, P. Transcription factor RAP2.2 and its interacting partner SINAT2: stable elements in the carotenogenesis of Arabidopsis leaves. Plant Physiol. 145, 1073-1085 (2007).

16. Francesco, L. et al. Oxygen sensing in plants is mediated by an $\mathrm{N}$-end rule pathway for protein destabilization. Nature 479, 419-422 (2011).

17. Oñate-Sánchez, L. \& Singh, K. B. Identification of Arabidopsis ethyleneresponsive element binding factors with distinct induction kinetics after pathogen infection. Plant Physiol. 128, 1313-1322 (2002).

18. Cao, Y., Song, F., Goodman, R. M. \& Zheng, Z. Molecular characterization of four rice genes encoding ethylene-responsive transcriptional factors and their expressions in response to biotic and abiotic stress. J. Plant Physiol. 163, 1167-1178 (2006)

19. Sharoni, A. M. et al. Gene structures, classification and expression models of the AP2/EREBP transcription factor family in rice. Plant Cell Physiol. 52, 344-360 (2011).

20. Zhang, G. et al. Phylogeny, gene structures, and expression patterns of the ERF gene family in soybean (Glycine max L.). J. Exp. Bot. 59, 4095-4107 (2008).

21. Zhuang, J. et al. Discovery and expression profile analysis of AP2/ERF family genes from Triticum aestivum. Mol. Biol. Rep. 38, 745-753 (2011).

22. Zhang, G. et al. Overexpression of the soybean GmERF3 gene, an AP2/ERF type transcription factor for increased tolerances to salt, drought, and diseases in transgenic tobacco. J. Exp. Bot. 60, 3781-3796 (2009).

23. Zhang, $\mathrm{H}$. et al. Functional analyses of ethylene response factor JERF3 with the aim of improving tolerance to drought and osmotic stress in transgenic rice. Transgenic Res. 19, 809-818 (2010).
24. Zhang, Z., Li, F., Li, D., Zhang, H. \& Huang, R. Expression of ethylene response factor JERF1 in rice improves tolerance to drought. Planta 232, 765-774 (2010).

25. Zhang, Z., Wang, J., Zhang, R. \& Huang, R. The ethylene response factor AtERF98 enhances tolerance to salt through the transcriptional activation of ascorbic acid synthesis in Arabidopsis. Plant J. 71, 273-287 (2012).

26. $\mathrm{Xu}, \mathrm{K}$. et al. Sub1A is an ethylene-response-factor-like gene that confers submergence tolerance to rice. Nature 442, 705-708 (2006).

27. Fukao, T., Xu, K., Ronald, P. C. \& Bailey-Serres, J. A variable cluster of ethylene response factor-like genes regulates metabolic and developmental acclimation responses to submergence in rice. Plant Cell 18, 2021-2034 (2006).

28. Fukao, T. \& Baileyserres, J. Submergence tolerance conferred by Sub1A is mediated by SLR1 and SLRL1 restriction of gibberellin responses in rice. Proc. Natl Acad. Sci. USA 105, 16814-16819 (2008).

29. Licausi, F. et al. HRE1 and HRE2, two hypoxia-inducible ethylene response factors, affect anaerobic responses in Arabidopsis thaliana. Plant J. 62, 302-315 (2010).

30. LV, Y., Fu, S., Chen, S., Zhang, W. \& Qi, C. Ethylene response factor BnERF2-like (ERF2.4) from Brassica napus L. enhances submergence tolerance and alleviates oxidative damage caused by submergence in Arabidopsis thaliana. Plant J. 4, 199-211 (2016).

31. Wang, $H$. et al. Transcriptome changes associated with delayed flower senescence on transgenic petunia by inducing expression of etr1-1, a mutant ethylene receptor. PLOS ONE 8, e65800 (2013).

32. Sun, D. et al. A petunia ethylene-responsive element binding factor, PhERF2, plays an important role in antiviral RNA silencing. J. Exp. Bot. 67, 3353-3365 (2016).

33. Zhang, $\mathrm{H}$. et al. The ethylene-, jasmonate-, abscisic acid- and NaCl-responsive tomato transcription factor JERF1 modulates expression of GCC boxcontaining genes and salt tolerance in tobacco. Planta 220, 262-270 (2004).

34. Yi, S. Y. et al. The pepper transcription factor CaPF1 confers pathogen and freezing tolerance in Arabidopsis. Plant Physiol. 136, 2862-2874 (2004).

35. Liang, Y. C., Reid, M. S. \& Jiang, C. Z. Controlling plant architecture by manipulation of gibberellic acid signalling in petunia. Hortic. Res 1, 14061 (2012).

36. Yin, J. et al. A basic helix-loop-helix transcription factor, $\mathrm{PhFBH4}$, regulates flower senescence by modulating ethylene biosynthesis pathway in petunia. Hortic. Res. 2, 15059 (2015).

37. Yin, D. M., Chen, S. M., Chen, F., Guan, Z. \& Fang, W. Morpho-anatomical and physiological responses of two Dendranthema species to waterlogging. Environ. Exp. Bot. 68, 122-130 (2010).

38. Chen, J. C. et al. Chalcone synthase as a reporter in virus-induced gene silencing studies of flower senescence. Plant Mol. Biol. 55, 521-530 (2004).

39. Reid, M. S., Chen, J. C. \& Jiang, C. Z. in Petunia. (eds Gerats, T. \& Strommer, J.) 381-394 (Springer, Berlin Heidelberg, 2009).

40. Liu, P., Wu, Z., Xue, H. \& Zhao, X. Antibiotics trigger initiation of SCCmec transfer by inducing SOS responses. Nucleic Acids Res 45, 3944-3952 (2017).

41. Chen, K. Liu, H., Lou, Q. \& Liu, Y. Ectopic expression of the grape hyacinth (Muscari armeniacum) R2R3-MYB transcription factor gene, MaAN2, induces anthocyanin accumulation in tobacco. Front. Plant Sci. 8, 965 (2017).

42. Yin, D., Zhang, Z. \& Luo, H. Anatomical responses to waterlogging in Chrysanthemum zawadskii. Sci. Hortic. 146, 86-91 (2012).

43. Ashraf, M. A. Waterlogging stress in plants: a review. Afr. J. Agr. Res. 7, 1976-1981 (2012).

44. Ahmed, S., Nawata, E., Hosokawa, M., Domae, Y. \& Sakuratani, T. Alterations in photosynthesis and some antioxidant enzymatic activities of mungbean subjected to waterlogging. Plant Sci. 163, 117-123 (2002).

45. Kumutha, D. et al. Waterlogging induced oxidative stress and antioxidant activity in pigeonpea genotypes. Biol. Plant. 53, 75-84 (2009).

46. Drew, M. C. \& Sisworo, E. J. Early effects of flooding on nitrogen deficiency and leaf chlorosis in barley. New Phytol. 79, 567-571 (1977).

47. Lee, J. H. et al. Functional characterization of NtCEF1, an AP2/EREBP-type transcriptional activator highly expressed in tobacco callus. Planta $\mathbf{2 2 2}$ 211-224 (2005).

48. Wang, $\mathrm{H}$. et al. Ectopic overexpression of tomato JERF3 in tobacco activates downstream gene expression and enhances salt tolerance. Plant Mol. Biol. 55, 183-192 (2004).

49. Suralta, R. R. \& Yamauchi, A. Root growth, aerenchyma development, and oxygen transport in rice genotypes subjected to drought and waterlogging. Environ. Exp. Bot. 64, 75-82 (2008).

50. Colmer, T. D. Long-distance transport of gases in plants: a perspective on internal aeration and radial oxygen loss from roots. Plant Cell Environ. 26 17-36 (2003). 
51. Finlayson, C. Plant ecology of Australia's tropical floodplain wetlands: a review. Ann. Bot. 96, 541-555 (2005).

52. Voesenek, L. A., Colmer, T. D., Pierik, R., Millenaar, F. F. \& Peeters, A. J. How plants cope with complete submergence. New Phytol. 170, 213-226 (2006).

53. Ashraf, M. Relationships between leaf gas exchange characteristics and growth of differently adapted populations of Blue panicgrass (Panicum antidotale Retz.) under salinity or waterlogging. Plant Sci. 165, 69-75 (2003).

54. Armstrong, W. The anatomical characteristics of roots and plant response to soil flooding. New Phytol. 106, 465-495 (1987).

55. Wang, W., Xiao, Y., Chen, L. \& Lin, P. Leaf anatomical responses to periodical waterlogging in simulated semidiurnal tides in mangrove Bruguiera gymnorrhiza seedlings. Aquat. Bot. 86, 223-228 (2007).

56. Das, K. K., Panda, D., Sarkar, R. K., Reddy, J. N. \& Ismail, A. M. Submergence tolerance in relation to variable floodwater conditions in rice. Environ. Exp. Bot. 66, 425-434 (2009).

57. Rich, S. M., Ludwig, M. \& Colmer, T. D. Photosynthesis in aquatic adventitious roots of the halophytic stem-succulent Tecticornia pergranulata (formerly Halosarcia pergranulata). Plant Cell Environ. 31, 1007-1016 (2008).

58. Rivoal, J. \& Hanson, A. D. Metabolic control of anaerobic glycolysis, overexpression of Lactate Dehydrogenase in transgenic tomato roots supports the davies-roberts hypothesis and points to a critical role for lactate secretion. Plant Physiol. 106, 1179-1185 (1994).

59. Nada, K. \& El-Mowafy, O. Effect of precuring warming on mechanical properties of restorative composites. Int. J. Dent. 2011, 536212 (2011).

60. Yin, D., Chen, S., Chen, F., Guan, Z. \& Fang, W. Morphological and physiological responses of two chrysanthemum cultivars differing in their tolerance to waterlogging. Environ. Exp. Bot. 67, 87-93 (2009).

61. Kang, Y. Y., Guo, S. R., Li, J. \& Duan, J. Effect of root applied 24epibrassinolide on carbohydrate status and fermentative enzyme activities in cucumber (Cucumis sativus L.) seedlings under hypoxia. Plant Growth Regul. 57, 259-269 (2009).

62. Yin, D., Chen, S., Chen, F. \& Jiang, J. Ethylene promotes induction of aerenchyma formation and ethanolic fermentation in waterlogged roots of Dendranthema spp. Mol. Biol. Rep. 40, 4581-4590 (2013).

63. Xu, Z. S., Chen, M., Li, L. C. \& Ma, Y. Z. Functions of the ERF transcription factor family in plants. Bot.-Bot. 86, 969-977 (2008).

64. Nakano, T., Suzuki, K., Fujimura, T. \& Shinshi, H. Genome-wide analysis of the ERF gene family in Arabidopsis and rice. Plant Physiol. 140, 411-432 (2006).

65. Hao, D., Ohme-Takagi, M. \& Sarai, A. Unique mode of GCC box recognition by the DNA-binding domain of ethylene-responsive element-binding factor (ERF domain) in plant. J. Biol. Chem. 273, 26857-26861 (1998).

66. Hinz, M. et al. Arabidopsis RAP2.2: an ethylene response transcription factor that is important for hypoxia survival. Plant Physiol. 153, 757-772 (2010).

67. Peeters, A. J. et al. Submergence research using Rumex palustris as a model; looking back and going forward. J. Exp. Bot. 53, 391-398 (2002).

68. Hattori, Y. et al. The ethylene response factors SNORKEL1 and SNORKEL2 allow rice to adapt to deep water. Nature 460, 1026-1030 (2009).

69. Mustroph, A. et al. Organ-specific analysis of the anaerobic primary metabolism in rice and wheat seedlings. I: Dark ethanol production is dominated by the shoots. Planta 225, 103-114 (2006).

70. Gunawardena, A., Pearce, D. M., Jackson, M. B., Hawes, C. R. \& Evans, D. E. Characterisation of programmed cell death during aerenchyma formation induced by ethylene or hypoxia in roots of maize (Zea mays L.). Planta $\mathbf{2 1 2}$ 205-214 (2001).

71. Perata, P. \& Voesenek, L. Submergence tolerance in rice requires Sub1A, an ethylene-response-factor-like gene. Trends Plant Sci. 12, 43-46 (2007). 